\title{
Modeled Respiratory Tract Deposition of Smoke Aerosol from Conventional Cigarettes, Electronic Cigarettes and Heat-not-burn Products
}

\author{
Yawen Li ${ }^{1}$, Huapeng Cui ${ }^{1 *}$, Li Chen ${ }^{1}$, Meijuan Fan ${ }^{1}$, Junlan Cai ${ }^{1}$, Junwei Guo ${ }^{1}$, \\ Caner U. Yurteri ${ }^{2}$, Xiaoxi $\mathrm{Si}^{3}$, Shaofeng $\mathrm{Liu}^{1}$, Fuwei Xie${ }^{1}$, Jianping $\mathrm{Xie}^{1}$ \\ ${ }^{1}$ Zhengzhou Tobacco Research Institute of CNTC, Zhengzhou, China \\ ${ }^{2}$ Research and Development, British American Tobacco Investments Ltd, Regents Park Road, \\ Southampton, Hampshire SO15 8TL, UK \\ ${ }^{3}$ RandD Center of China Tobacco Yunnan Industrial Co., Ltd., Kunming, China
}

\section{ABSTRACT}

Knowledge of the deposition of inhaled smoke aerosol in the human respiratory tract has great value for risk assessments of the inhalation toxicology of tobacco products. In this study, differential mobility spectrometry (DMS) was used to characterize smoke particles generated from a conventional cigarette, e-cigarette and heat-not-burn product. The aerosol properties obtained by DMS were then applied to a Multiple Path Particle Dosimetry (MPPD) model to predict the deposition of aerosol particles in the human respiratory tract. The DMS results showed that the particle size distribution of aerosol from the three products differed considerably, with a count median diameter of 14.2-25.4 nm, 50.6-55.3 nm and 172-179 nm for the e-cigarette, heat-not-burn product and conventional cigarette, respectively. However, there was no significant difference in the particle number concentration of aerosol from the three products. The MPPD model indicated that the total deposition fraction of aerosol particles from the e-cigarette and heat-not-burn product was higher than that from the conventional cigarette, and deposition of particles from the e-cigarette in the three human airway regions (head airway, tracheobronchial and pulmonary regions) was higher than that from the heat-not-burn product and conventional cigarette; the particle number concentration deposited in the pulmonary region was the highest, comprising more than $60 \%$ of total deposition. Lastly, among the lung lobes, the highest number deposition fraction occurred in the right lower lobe. The relationship between deposition fraction and airway generation was relatively similar among the three aerosols, and the highest deposition fraction occurred in the $20^{\text {th }}$ to $23^{\text {rd }}$ generation airways. The deposition results showed that smaller particles, such as those from the e-cigarette aerosol, were more easily deposited in the human respiratory tract. Combined with knowledge of the harmful aerosol constituents, these deposition data will provide important information for hazard evaluation of new tobacco products.

${ }^{*}$ Corresponding Author: cuihuapeng516@126.com

Publisher:

Taiwan Association for Aerosol Research

ISSN: $1680-8584$ print

ISSN: 2071-1409 online

(c) Copyright: The Author(s).

This is an open access article distributed under the terms of the Creative Commons Attribution License (CC BY 4.0), which permits unrestricted use, distribution, and reproduction in any medium, provided the original author and source are cited.

Keywords: Conventional cigarette, E-cigarette, Heat-not-burn product, Aerosol property, Respiratory tract, MPPD-modeled deposition

\section{INTRODUCTION}

Numerous studies have confirmed the health risks of cigarette smoking, which is generally considered to be the leading preventable cause of various diseases, such as lung cancer, cardiovascular disease and stroke (Church et al., 2009; Barua and Ambrose, 2013; Hackshaw et al., 2018; WHO, 2008). The pathogenic substances mainly stem from the cigarette smoke generated by tobacco consumption. There are more than 7000 chemical constituents in cigarette smoke (Rodgman and Perfetti, 2008), including hundreds of toxins and carcinogens (Baker, 2006; 
Geiss and Kotzias, 2007). In recent years, new types of product have emerged in the tobacco market. In particular, products such as e-cigarettes and heat-not-burn ( $\mathrm{HnB}$ ) products are becoming increasing popular owing to their claimed function of being able to reduce or even eliminate toxicity or mutagenicity of cigarette smoke (Chen, 2017; Simonavisius et al., 2018; Boue et al., 2020).

It is the chemicals carried by smoke particles that are associated with disease (U.S. Department of Health and Human Services, 2014). However, it is insufficient to assume that the lower yield of chemical components produced by new tobacco products is less harmful. In general, cigarette smoke particles are typically sub-micron and easily deposited in the human respiratory tract during smoking. The physical properties of the aerosol are likely to affect the deposition of particles and further affect the retention of chemicals, which is an important aspect of the health risks of smoking. Furthermore, smaller particles may be deposited more deeply in the human respiratory tract (Carvalho et al., 2011). Therefore, smoke exposure and hazard evaluation should not only focus on the chemicals, but also account for the deposition of aerosol particles.

A few studies have investigated the deposition of environmental or smoke aerosol particles in human airways. For example, Martins et al. (2010) simulated the deposition of atmospheric fine particles in the human airway. Patterson et al. (2014) also evaluated the deposition of environmental ultrafine particles in the respiratory tracts of school-aged children. Regarding smoke aerosol, Zhe et al. (2012) analyzed the deposition of cigarette smoke particles in the human upper airways, Zhang et al. (2012), Pichelstorfer et al. (2016) and Sosnowski et al. (2016) predicted the deposition of smoke particles from e-cigarettes and conventional cigarettes. Moreover, Protano et al. (2017) investigated the second-hand smoke generated by conventional cigarettes, e-cigarettes and $\mathrm{HnB}$ products.

Those studies have provided a better understanding of particle deposition in the respiratory tract. To our knowledge, however, there has been no comprehensive comparison of the deposition of smoke particles between conventional cigarettes and modern tobacco products (e-cigarettes and $\mathrm{HnB}$ products) as yet, especially in terms of number concentration (NC) deposition in the regional and whole airways. As compared with conventional cigarettes, the aerosol generated from e-cigarettes and $\mathrm{HnB}$ products may have different physical properties, leading to different doses of respiratory deposition. Thus, it is necessary and significant to determine the physical properties of aerosol particles from these products, and use them to estimate the deposition dose of particles in the human airways, which might be applied to comprehensive assessment of the health risks of new tobacco products.

The physical properties of an aerosol, including particle NC, count median diameter (CMD) and geometric standard deviation (GSD) among others, are important parameters for estimating the deposition dose of the particles. To predict the deposition of the smoke particles in the human respiratory tract, therefore, these physical properties must be measured accurately (Kane et al., 2010; Sahu et al., 2013). Methods for the characterization of smoke particles have been developed since the 1970s. Kijowski (1985) reviewed early approaches to smoke particle size, including microscopy (Holmberg and Yeatts, 1976), centrifugation (Hinds, 1978), an aerodynamic particle sizer (McCusker et al., 1982), and a light scattering technique (Leaderer et al., 1984), among others. More recently, differential mobility spectrometry (DMS) has been developed for real-time measurements of the particle size distribution of cigarette smoke (Adam et al., 2009; Alderman and Ingebrethsen, 2011; Cui et al., 2020). DMS is based on the difference in electro migration of charged particles in an electric field, and can be used to measure both particle number and particle size distribution, as described in detail by Symonds et al. (2007).

Using DMS, Adam (2009) reported that cigarette smoke aerosol has a CMD of 180-280 nm, and a particle NC of $1.4 \times 10^{9}$ to $1.5 \times 10^{10} \mathrm{~N} \mathrm{~cm}^{-3}$. Alderman and Ingebrethsen (2011) combined DMS with a smoking cycle simulator (SCS) to characterize the smoke aerosol from 29 different brands of cigarettes under intense (puff volume $60 \mathrm{~mL}$, duration $2 \mathrm{~s}$, puff interval $30 \mathrm{~s}$ ) and standard (puff volume $35 \mathrm{~mL}$, duration $2 \mathrm{~s}$, puff interval $30 \mathrm{~s}$ ) smoking regimes, reporting that the CMD of particles generated under the intense smoking regime was 145-189 nm, which was 12$22 \mathrm{~nm}$ smaller than that generated under the standard smoking regime. Duan et al. (2015) compared the smoke aerosol particles of conventional cigarettes and e-cigarettes by DMS, showing that the particle size of e-cigarette aerosols was smaller than that of conventional cigarettes. Similarly, Si et al. (2018) investigated the physical properties of HnB aerosols, finding 
that the particle size of $\mathrm{HnB}$ aerosol was smaller than that of conventional cigarette smoke.

Regarding particle deposition, various computational models have been formulated to predict the respiratory-tract dosimetry of inhaled particles. These models are generally mathematically complex and multidisciplinary. Many are based on a lung structure constructed from actual airway measurements, combined with experimental investigations and a series of calculations to predict particle deposition, such as Computational Fluid-Particle Dynamics (CF-PD) simulation models (Rostami, 2009; Kleinstreuer and Zhang, 2010; Hofmann, 2011; Sosnowski, 2011; Kleinstreuer and Feng, 2013), the ICRP dosimetry model (Bair, 1995; Mellat et al., 2017) and the Multiple Path Particle Dosimetry (MPPD) model (Martins et al., 2010; Li et al., 2016). Among these models, the MPPD model is based on realistic lung geometry, physiology and deposition mechanisms, and it provides estimates of both the whole-lung and the regional particle deposition fractions that have been validated with experimental data (Rostami, 2009). In addition, the MPPD dosimetry model is freely available to the public (http://www.ara.com/products/mppd.htm), and has user-friendly menu-driven selections to aid input of the study variables (Anjilvel and Asgharian, 1995; Miller et al., 2016).

The MPPD model has been used to estimate the deposition of inhaled particles in different regions of the human respiratory tract. For example, Liang et al. (2017) employed a wide-range particle spectrometer to characterize smoke aerosols and applied the data to the MPPD model to analyze the deposition fraction and concentration of fine particles in various regions of the human respiratory system. Sahu et al. (2013) used the MPPD model to study the deposition fraction of cigarette smoke in the human head airway, and tracheobronchial and alveolar regions. In addition, Manigrasso et al. (2015) carried out a detailed investigation into the deposition distribution of e-cigarette aerosol in human alveoli based on the MPPD model.

As mentioned above, comprehensive health risk assessment of tobacco products should also consider the deposition of aerosol particles in the human airways. In this paper, therefore, the physical properties of aerosols from conventional cigarettes, e-cigarettes, and $\mathrm{HnB}$ products were measured by SCS-DMS and the results were applied to the MPPD model to evaluate the regional and total distribution of aerosol particles deposited in the human respiratory tract.

\section{MATERIALS AND METHODS}

\subsection{Samples}

In total, nine commercially available tobacco products were assessed in this study, including conventional cigarettes with different tar content $(n=3)$, and different types of e-cigarettes $(n=$ 3 ) and $\mathrm{HnB}$ products $(n=3)$. Information on the nine products is summarized in Table 1.

The conventional cigarettes were conditioned at $22 \pm 1^{\circ} \mathrm{C}$ and $60 \pm 3 \%$ relative humidity (RH) for more than 48 hours before analysis; the e-cigarettes and $\mathrm{HnB}$ products were test directly after being taken out of the package. Measurements were performed under the ambient laboratory conditions at $24 \pm 3^{\circ} \mathrm{C}$ and $45 \pm 5 \% \mathrm{RH}$.

Table 1. Tobacco products analyzed in this study.

\begin{tabular}{ll}
\hline Product No. & Details \\
\hline Conventional cigarette & \\
$\# 1$ (3R4F) & Tar $9.4 \mathrm{mg}$ \\
$\# 2$ & Tar $5.0 \mathrm{mg}$ \\
$\# 3$ & Tar $11.0 \mathrm{mg}$ \\
E-cigarette & \\
$\# 4$ & Disposable \\
$\# 5$ & Cartomizer \\
$\# 6$ & Rechargeable \\
Heat-not-burn product & \\
$\# 7$ & Internal heating \\
$\# 8$ & Internal heating \\
$\# 9$ & External heating \\
\hline
\end{tabular}




\subsection{Smoke Aerosol Characterization}

The properties of the aerosol generated by all products were measured by an SCS-DMS system (Fig. 1), which has been previously described in detail by Alderman and Ingebrethsen (2011). In brief, the SCS is used to simulate various puff profiles and to accurately control the flow rate, while DMS is used to measure the particle NC and size distribution of the aerosol. The instrument has 38 channels and can classify particle size ranging from 5 to $1000 \mathrm{~nm}$.

For the conventional cigarettes and HnB products, the ISO puffing regime (bell profile; puff volume, $35 \mathrm{~mL}$; puff duration, $2 \mathrm{~s}$; puff interval, $60 \mathrm{~s}$ ) (ISO, 2000) was used; for the e-cigarettes, the ISO puffing regime (square profile; puff volume, $55 \mathrm{~mL}$; puff duration, $3 \mathrm{~s}$; puff interval, $30 \mathrm{~s}$ ) (ISO 20768: 2018) was used. The following conditions were used: initial sampling flow rate of SCSDMS, $25 \mathrm{~L} \mathrm{~min}{ }^{-1}$; sampling flow rate of DMS, $8 \mathrm{~L} \mathrm{~min}{ }^{-1}$; secondary dilution ratio, 1:200; sampling head temperature, $40^{\circ} \mathrm{C}$; sheath gas temperature, $40^{\circ} \mathrm{C}$; cyclone separator temperature, $80^{\circ} \mathrm{C}$; acquisition frequency of DMS, $10 \mathrm{~Hz}$. All products were tested under these experimental conditions.

\subsection{MPPD-modeled Particle Deposition}

To predict the deposition of aerosol particles in the human respiratory tract, the DMS aerosol data (i.e., NC, CMD, GSD) of the samples were averaged and entered into MPPD version 3.04, a computational model jointly developed by the American Hamna Health Research Institute and the National Institute of Public Health and Environment of the Netherlands. MPPD can calculate particle deposition in the respiratory tract of humans (adults and children), rats, pigs and monkeys for monodisperse and polydisperse aerosols with particle sizes ranging from 0.001 to $100 \mu \mathrm{m}$, and its detailed function is described on its official website.

The modeled deposition is based on single-path or multiple-path methods for tracking air flow and calculating aerosol deposition in the lung. In this study, the multiple-path method was chosen because it essentially reflects the real structure of the human respiratory system, as explained in detail by Anjilvel and Asgharian (1995). For the human lung, there are several options for lung geometry, including Yeh-Schum single path, Yeh-Schum 5-lobe, stochastic model, age-specific symmetric model, age-specific 5-lobe model, Weibel symmetric model, PNNL symmetric model, and PNNL asymmetric model. On the basis of published reports (Roy et al., 1991; Li et al., 2016), the stochastic model was employed with lung size set at the $60^{\text {th }}$ percentile to predict the aerosol distribution and deposition in the Chinese adult respiratory tract. The following parameters were applied to MPPD: functional residual air volume, $2950 \mathrm{~mL}$; upper respiratory tract volume, $44.7 \mathrm{~mL}$;

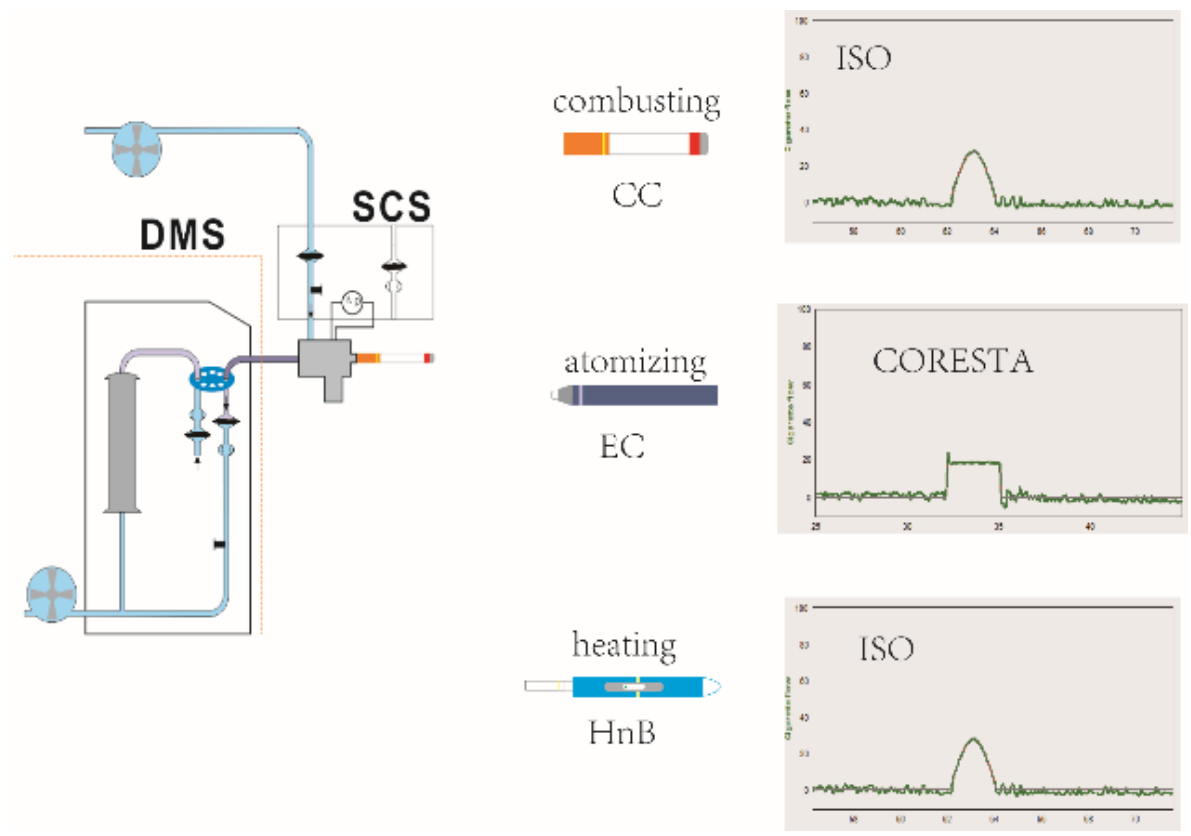

Fig. 1. Schematic diagram showing the characterization of aerosol from a conventional cigarette $(C C)$, e-cigarette $(E C)$ and heat-not-burn $(\mathrm{HnB})$ product under different smoking regimes. 
tidal volume, $537.5 \mathrm{~mL}$. The duration of a single puff was set as $5 \mathrm{~s}$ with $2 \mathrm{~s}$ inhalation, $1 \mathrm{~s}$ pause, and $2 \mathrm{~s}$ exhalation, and the breathing condition was set as oral breathing. The other parameters were the default values in the model.

DMS provides the size distributions of aerosol particles in terms of particle electrical mobility diameter and $\mathrm{NC}\left(\mathrm{N} \mathrm{cm}^{-3}\right)$; however, the input data for the MPPD model needs to be particle aerodynamic diameter. Previously, Hinds (1999) proposed Eq. (1) to convert particle electrical mobility diameter to aerodynamic diameter:

$$
D_{a}=D_{m} \sqrt{\chi C_{s}\left(D_{m}\right) \rho_{p} / C_{s}\left(D_{a}\right) \rho_{0}}
$$

where $D_{\mathrm{a}}$ and $D_{\mathrm{m}}$ are the particle aerodynamic diameter $(\mathrm{nm})$ and particle electrical mobility diameter $(\mathrm{nm})$, respectively; $\chi$ is the shape factor, $C_{\mathrm{s}}$ is the Cunningham slip correction factor for a certain diameter; $\rho_{p}$ is the density of the particles and $\rho_{0}$ is the reference density $\left(1 \mathrm{~g} \mathrm{~cm}^{-3}\right)$. The shape factor is assumed as 1 for spherical cigarette smoke particles (Johnson et al., 2015). Both the electrical mobility diameter and aerodynamic diameter require correction, and the correction factors are found to be similar. The Cunningham slip factor is neglected. We estimated the error introduced by neglecting the Cunningham slip factor to be $8 \%$ for particles smaller than $10 \mathrm{~nm}$, a maximum of $5 \%$ for particle sizes between 10 and $50 \mathrm{~nm}$, a maximum of $3 \%$ for particle sizes between 50 and $100 \mathrm{~nm}$, and smaller than 1\% for particles larger than $500 \mathrm{~nm}$. Therefore, neglection will not introduce a significant error for particle sizes larger than $1 \mu \mathrm{m}$. Thus, the relationship between $D_{\mathrm{m}}$ and $D_{\mathrm{a}}$ will become:

$D_{a}=D_{m} \sqrt{\rho_{p}}$

The effective density of cigarette smoke particles is $1.18 \mathrm{~g} \mathrm{~cm}^{-3}$ (Johnson et al., 2015). Thus,

$D_{a}=1.09 \times D_{m}$

Therefore, the particle aerodynamic diameter is used to discuss our findings (except for the DMS measurement data).

To our knowledge, however, there are no reports of the effective density of aerosol particles from e-cigarettes or $\mathrm{HnB}$ products. The aerosol from an e-cigarette mainly comprises glycerol ( $\rho$, $\left.1.26 \mathrm{~g} \mathrm{~cm}^{-3}\right)$ and propylene glycol $\left(\rho, 1.03 \mathrm{~g} \mathrm{~cm}^{-3}\right)$, whereas that from an $\mathrm{HnB}$ product comprises glycerol and other tobacco constituents. Approximately, therefore, the effective density of aerosol particles among the three products should be similar. Therefore, a $\rho_{p}$ value of $1.18 \mathrm{~g} \mathrm{~cm}^{-3}$ was used for MPPD modeling in this study.

The aerosol particle hygroscopic growth, evaporation-coagulation (Asgharian et al., 2014, 2018; Sosnowski and Odziomek, 2018) and the colligative motion (Broday and Robinson, 2003) of concentrated aerosols have a certain influence on local particle deposition in the respiratory system; however, it should be noted that the MPPD modeled deposition here focused on a comparison of the three kinds of tobacco product. The estimation produced by the modeling process is based on a few assumptions and neglection of thermodynamic and kinetic reactions (e.g., hygroscopic growth and coagulation).

\section{RESULTS AND DISCUSSION}

\subsection{Physical Properties of the Aerosol from Conventional Cigarettes, e-cigarettes, and HnB Products}

Initially, the physical properties of three different sample aerosols were measured by SCS-DMS over a puff number of 6,10 , and 6 for one conventional cigarette $(\# 1,3 R 4 F$, a standard reference cigarette developed by the University of Kentucky Centeror Tobacco Reference Products that is used throughout the tobacco industry and academic laboratories as a consistent and uniform test item for inhalation toxicology research), one e-cigarette (\#4), and one HnB product (\#7), respectively. The DMS data showed that the CMD and GSD of the three products remained 
essentially the same across the puffs; and the NC of the 3R4F cigarette and HnB product tended to increase with puff number, while that of e-cigarette did not vary with puff number (Fig. S1S3). The increase of particle number concentration for 3R4F cigarette was due to the decreased filtering effect of the tobacco rod with puff number (Adam et al., 2009). For HnB product, the increase of particle number concentration was attributed to the increase in temperature of the heater with puff number. For e-cigarette, the power for atomization of e-liquid was fixed for each puff, which keeps constant atomization temperature and produces the same aerosol.

Fig. 2 shows the puff-by-puff particle size distribution of aerosol from the 3R4F cigarette, e-cigarette and $\mathrm{HnB}$ product. In general, the aerosols of the 3R4F cigarette, e-cigarette and $\mathrm{HnB}$ all showed a single-peak log-normal distribution, and this distribution did not vary significantly variation among the puffs taken. For 3R4F, the particle size of the smoke was mainly concentrated in the range $50-600 \mathrm{~nm}$, and was close to $200 \mathrm{~nm}$ at the peak concentration. The concentration of smoke particles tended to increase with increasing puff number. For the e-cigarette, the particle size of the aerosol was in the range 5-150 nm, and was close to $20 \mathrm{~nm}$ at the highest concentration; unlike 3R4F, the concentration of aerosol particles did not change significantly with increasing the puff number. Lastly, the particle size of the HnB aerosol was mainly concentrated in range 10$200 \mathrm{~nm}$, and was close to $50 \mathrm{~nm}$ at the highest concentration; similar to 3R4F, the concentration of aerosol particles showed an increasing trend with increasing puff number.

All nine tobacco products were subjected to SCS-DMS; for each product, the results for each puff were averaged to obtain the mean physical properties of the aerosol (Table 2). The NC of aerosol particles ranged from $4.55 \times 10^{9}$ to $1.12 \times 10^{10} \mathrm{~N} \mathrm{~cm}^{-3}$ for conventional cigarettes, $5.75 \times$ $10^{9}$ to $8.27 \times 10^{9} \mathrm{~N} \mathrm{~cm}^{-3}$ for e-cigarettes, and $1.23 \times 10^{9}$ to $8.01 \times 10^{9} \mathrm{~N} \mathrm{~cm}^{-3}$ for HnB products. Overall, the NC of aerosol particles varied greatly among different products, thus, it seems more likely that NC is related to the design parameters of the product itself.

There was a more obvious difference in particle size among the three product types with size increasing in the following order: e-cigarettes (CMD, 14.2-25.4 nm) < HnB cigarettes (CMD, 50.6$55.3 \mathrm{~nm}$ ) < conventional cigarettes (CMD, 172-179 nm). This trend is mainly due to differences in the mechanism of aerosol generation of the three product types. Conventional cigarette tobacco has a high combustion temperature and the smoke contains a large quantity of solid particles and high-boiling-point organics, which can readily to form relatively large particles. The temperature of tobacco in the $\mathrm{HnB}$ product typically reaches $200-350^{\circ} \mathrm{C}$ during the heating process; at this temperature, volatile and semi-volatile organic compounds in the tobacco matrix are released, which form relatively small particles during the process of condensation. During aerosol formation in e-cigarette, the e-liquid completely vaporizes and then condenses into tiny droplets. Because the atomization process does not produce solid particles and the nucleation rate of the minute droplets is slow, the particle size is smaller for e-cigarettes. Lastly, there was no obvious difference in GSD among the three product types.

\subsection{Deposition of Aerosols in the Human Respiratory Tract}

To predict the deposition and distribution of aerosol particles in the human respiratory tract, the aerosol properties determined for one of each product type were applied to the MPPD model: convention cigarette \#1 (3R4F), e-cigarette \#4 and HnB product \#7. For these three products, the particle NC of aerosol was $8.35 \times 10^{9}, 6.14 \times 10^{9}$ and $8.01 \times 10^{9} \mathrm{~N} \mathrm{~cm}^{-3}$, respectively; the CMD was $172,25.4$ and $55.3 \mathrm{~nm}$, respectively; and the GSD was 1.41, 1.77 and 1.53, respectively. For the density of cigarette smoke particles, we used the value of $1.18 \mathrm{~g} \mathrm{~cm}^{-3}$ reported by Johnson et al. (2015), and assumed that this value would be valid for the density of aerosol particles generated from the e-cigarette and $\mathrm{HnB}$ product.

\subsection{Deposition of Aerosol in Different Regions of the Human Respiratory Tract}

The above DMS measurements showed that the particle size of aerosol from the three products ranged from $1 \mathrm{~nm}$ (e-cigarette) to $1 \mu \mathrm{m}$ (conventional cigarette). As shown in Fig. 3, the MPPD deposition model shows that the particle size of an aerosol plays an important role in the total deposition and the deposition fractions in different regions of the human respiratory tract. For example, the deposition fraction of particles ranging from 20 to $1000 \mathrm{~nm}$ is higher in the pulmonary region than in tracheobronchial region or head region. 
a

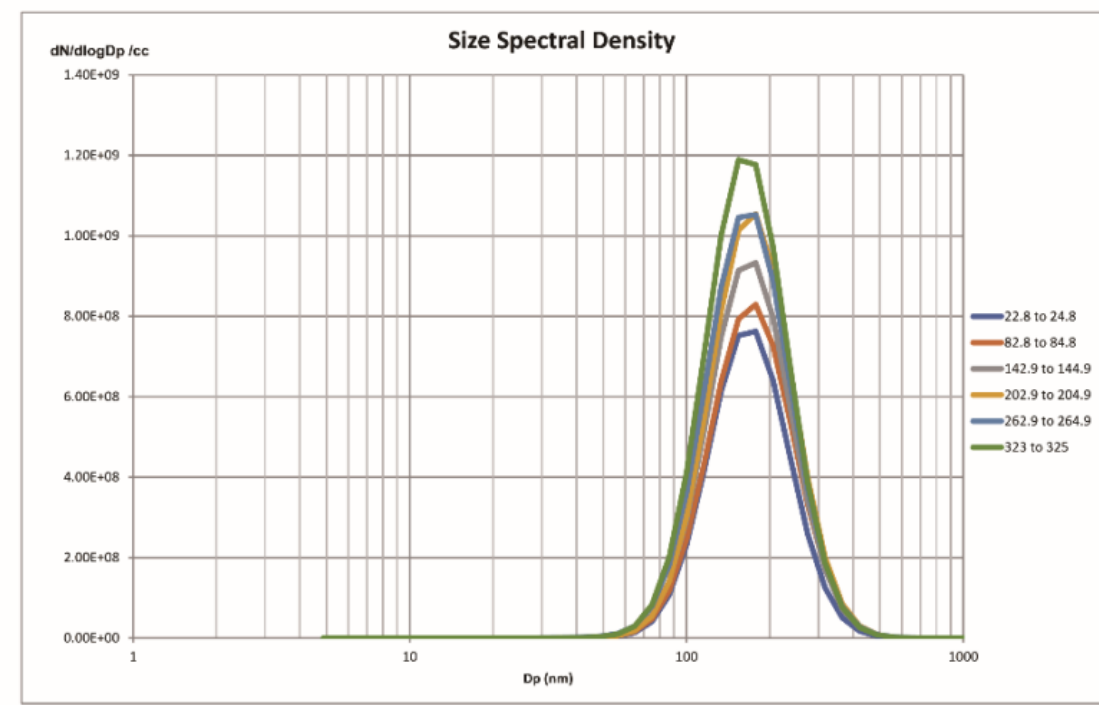

b

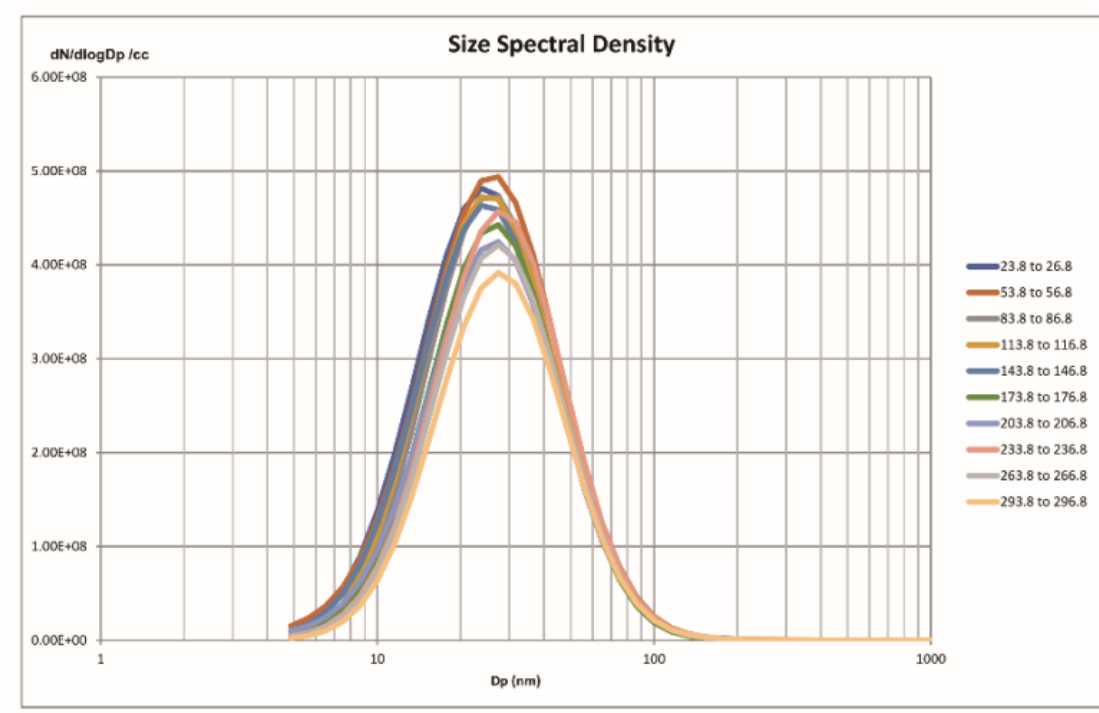

C

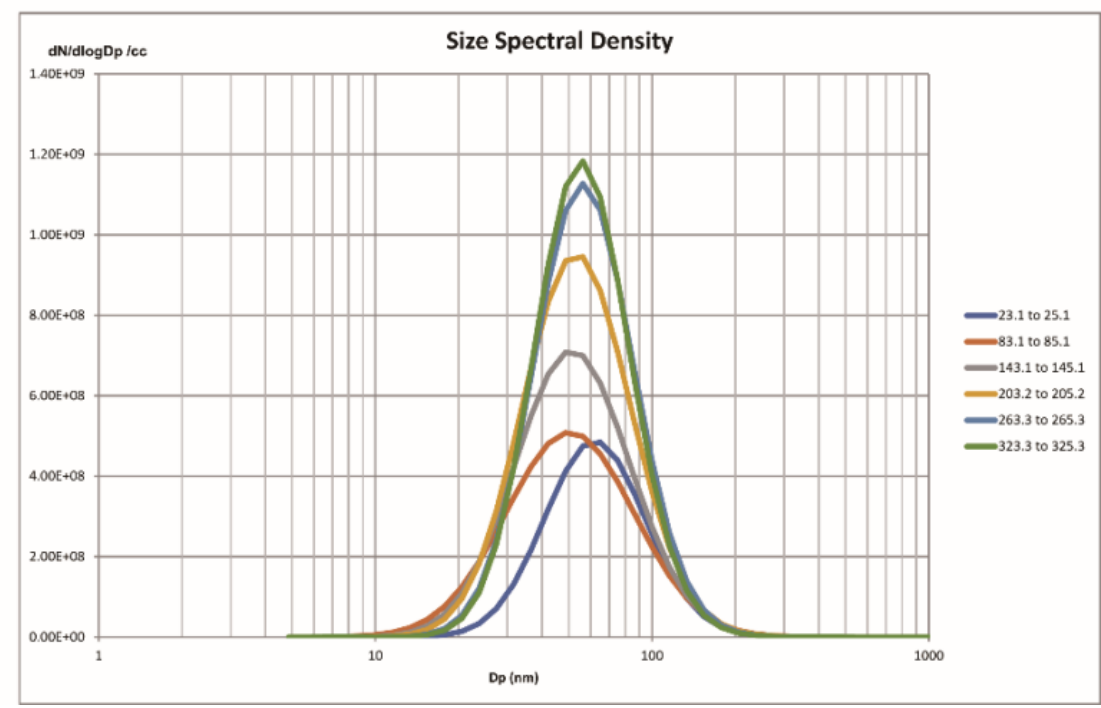

Fig. 2. Puff-by-puff particle size distribution in mainstream aerosol from three different tobacco products. (a) CC \#1 (3R4F); (b) EC \#4; (c) HnB \#7. The numbers in the key indicate the time when each 2-s puff was taken. 
Table 2. Particle NC and distribution data of the aerosol generated by the three products.

\begin{tabular}{llll}
\hline Product & Particle NC $\left(\mathrm{N} \mathrm{cm}^{-3}\right)$ & CMD $(\mathrm{nm})$ & GSD \\
\hline Conventional cigarette & & & \\
\#1 (3R4F) & $8.35 \times 10^{9}$ & 172 & 1.41 \\
$\# 2$ & $4.55 \times 10^{9}$ & 177 & 1.43 \\
$\# 3$ & $1.12 \times 10^{10}$ & 179 & 1.43 \\
E-cigarette & & & \\
$\# 4$ & $6.14 \times 10^{9}$ & 25.4 & 1.77 \\
$\# 5$ & $8.27 \times 10^{9}$ & 22.3 & 1.86 \\
$\# 6$ & $5.75 \times 10^{9}$ & 14.2 & 1.60 \\
Heat-not-burn product & & & \\
7\# & $8.01 \times 10^{9}$ & 55.3 & 1.53 \\
8\# & $4.71 \times 10^{9}$ & 55.0 & 1.62 \\
9\# & $1.23 \times 10^{9}$ & 50.6 & 2.55 \\
\hline
\end{tabular}

Abbreviations: CMD, count median diameter; GSD, geometric standard deviation; NC, number concentration.

All data were puffs averaged.

Convential cigarette: $n=3,6$ puffs; e-cigarette: $n=3,10$ puffs; heat-not-burn product: $n=3,6$ puffs.

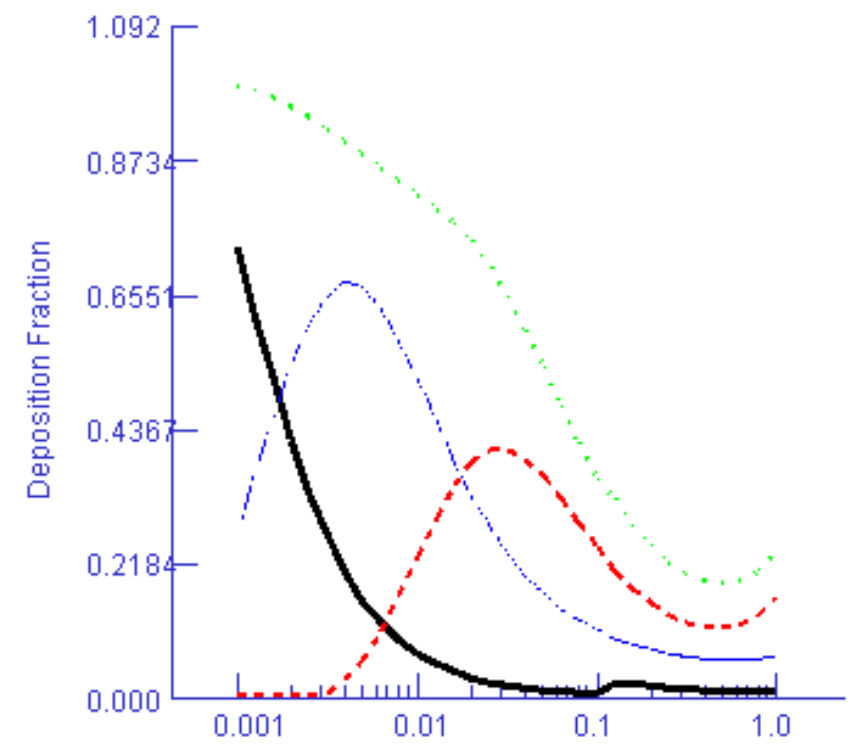

$$
\begin{aligned}
& \text { - Head } \\
& - \text { TB } \\
& -- \text { P } \\
& \text {. Total }
\end{aligned}
$$

Species \& Model Info: Species/Geometry: Human Stochastic FRC Volume: $2950.00 \mathrm{ml}$ Head volume: $44.70 \mathrm{ml}$ Breathing Route: oral

Breathing Parameters: Tidal Wolume: $537.50 \mathrm{ml}$ Breathing Frequency: $12.001 /$ min Inspiratony Fraction: 0.40 Pause Fraction: 0.20

Particle Properties:

Diameter: Multiple Diameters GSD: 1.00

Concentration: $1.00 \mathrm{mg} / \mathrm{m}^{3} 3$

\section{Particle Diameter ( $(\mu m)$}

Fig. 3. MPPD-modeled deposition fraction of aerosol in different respiratory regions by particle size. Abbreviations: TB, tracheobronchial region; $P$, pulmonary region.

The deposition fraction of aerosol particles from the three kinds of tobacco product in different regions of the human respiratory tract is shown in Fig. 4. For all three products, the fraction of particle deposition in the various regions showed the trend: head airway $<$ tracheobronchial region < pulmonary region. The deposition fraction in the head was the lowest, accounting for $4.0 \%-6.2 \%$ of the total airway deposition. Deposition in this region would be mainly due to the diffusion of aerosol particles in the oral cavity. As the aerosol is drawn into the tracheobronchial region, the passage narrows, causing the flow rate to increase, and as a result particle deposition increases. Deposition in this region accounted for $\sim 30 \%$ of the total airway deposition. When the aerosol enters the lungs, the closer contact with the pulmonary alveoli and the narrower and longer moving path further increases particle deposition; particle deposition in the alveoli accounted for about $60 \%$ of the total airway deposition. 


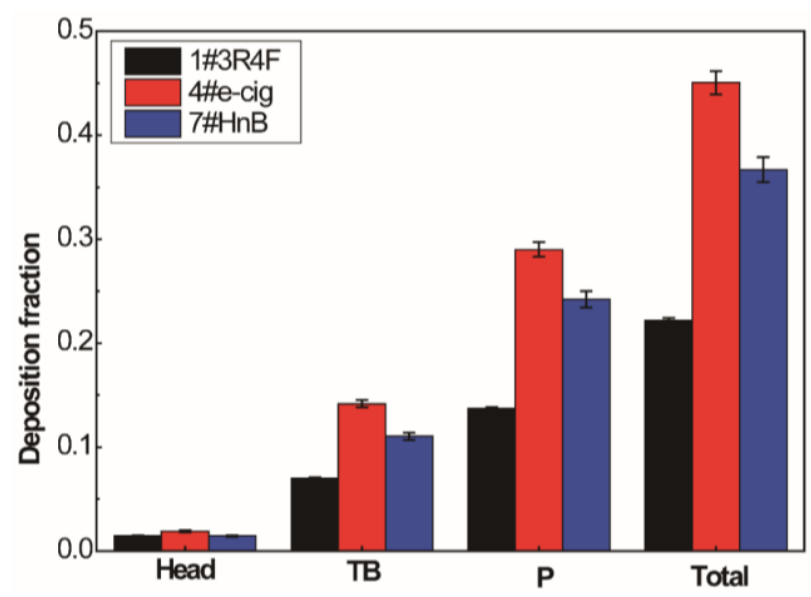

Fig. 4. Fraction of deposition in the head airways, tracheobronchial (TB) region and pulmonary (P) region, and total deposition of aerosol particles from the CC, EC and HnB.

Regarding the three tobacco products, the e-cigarette aerosol had the highest deposition fraction both in total and in each of the three respiratory regions. Deposition in the head airways followed the order: e-cigarette > conventional cigarette > HnB product; and deposition in the tracheobronchial and pulmonary regions, and in total followed the order: e-cigarette $>\mathrm{HnB}$ product $>3 \mathrm{R} 4 \mathrm{~F}$ cigarette. Moreover, the total deposition fraction of the e-cigarette aerosol was 1.23 times that of the $\mathrm{HnB}$ product, and 2.03 times that of the conventional cigarette. Therefore, the e-cigarette has a higher deposition fraction in the human respiratory tract relative to the $\mathrm{HnB}$ product and conventional cigarette, which is mainly due to the particle size distribution of the aerosol. That is to say, smaller particles are more easily deposited in all regions of the human respiratory tract.

The total particle number deposition fraction in the human airways was estimated as $1.85 \times$ $10^{9} \mathrm{~N} \mathrm{~cm}^{-3}, 2.76 \times 10^{9} \mathrm{~N} \mathrm{~cm}^{-3}$ and $2.94 \times 10^{9} \mathrm{~N} \mathrm{~cm}^{-3}$ for the cigarette, e-cigarette and HnB product, respectively. Thus, the total number deposition fraction was comparable between the e-cigarette and $\mathrm{HnB}$ product, and slightly lower for the $3 \mathrm{R} 4 \mathrm{~F}$ cigarette. Studies have shown that the smaller the particles, the more toxic the effects (Delfino et al., 2010; Meng et al., 2013), and that the NC has a greater impact on health (Penttinen et al., 2001). Notably, the NC of all three aerosols was much higher than that of air aerosol in the most heavily polluted day (Li et al., 2016).

Fig. 5 shows the distribution of particle number deposition fraction in different regions of the human respiratory tract by particle size. For all three tobacco products, the size distributions of NC exhibited a unimodal distribution, peaking at around 200,25 and $50 \mathrm{~nm}$ for the $3 R 4 \mathrm{~F}$ cigarette, e-cigarette and HnB product, respectively. Among the respiratory regions, deposition in the pulmonary region was the highest, accounting for $60 \%$ of total inhaled particles, while that in the head airways was the lowest. Comparing the NC size distribution of the three tobacco products, the number deposition fraction in the pulmonary and tracheobronchial regions was larger for the $\mathrm{HnB}$ product than for both the $3 \mathrm{R} 4 \mathrm{~F}$ cigarette and e-cigarette, while the opposite trend was observed in the head airways. The number deposition fraction had a similar peak value in the pulmonary region for the 3R4F cigarette and e-cigarette, but was higher in the head for the 3R4F cigarette and higher in the tracheobronchial region for the e-cigarette. The observed differences among the three types of product might be due to the mechanisms underlying particle deposition. The particles in 3R4F cigarette smoke are larger and thus more likely to be deposited in the head airway by impaction, whereas smaller particles can easily permeate into and deposit in the alveolar and pulmonary regions (Geiser et al., 2005).

\subsection{Deposition of Aerosol in the Human Lungs}

The MPPD model was used to predict the deposition of aerosol in different parts of the human lungs. The lungs comprise the left lung and the right lung; the left lung is split by the oblique fissure into the upper and lower lobes, while the right lung is divided into upper, middle and lower lobes. Overall, the patterns of deposition in the different lung lobes were relatively consistent for 

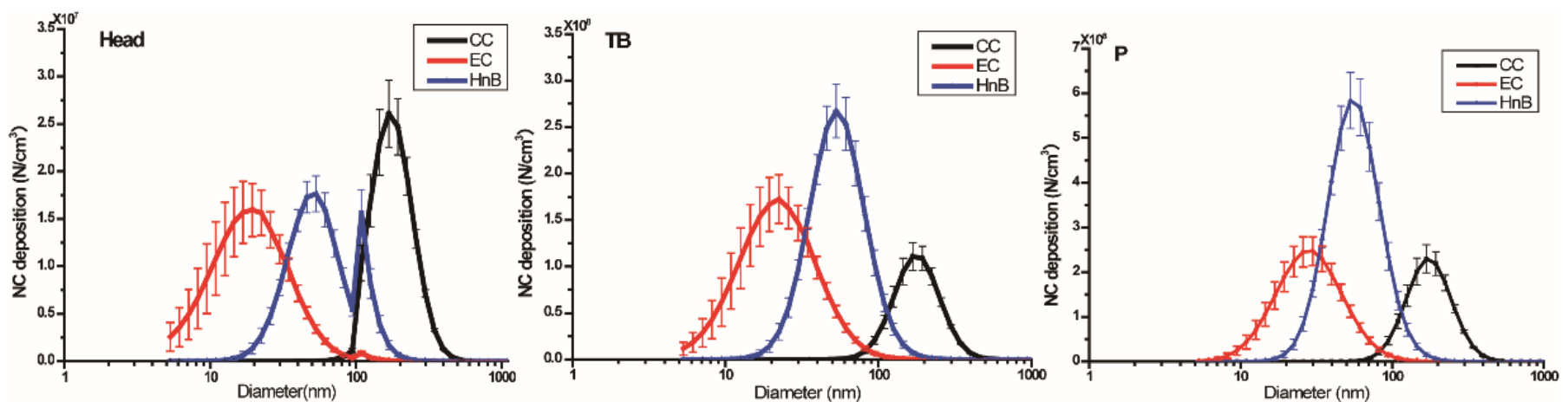

Fig. 5. Particle NC size deposition in the human airways for the CC, EC and $\mathrm{HnB}$.

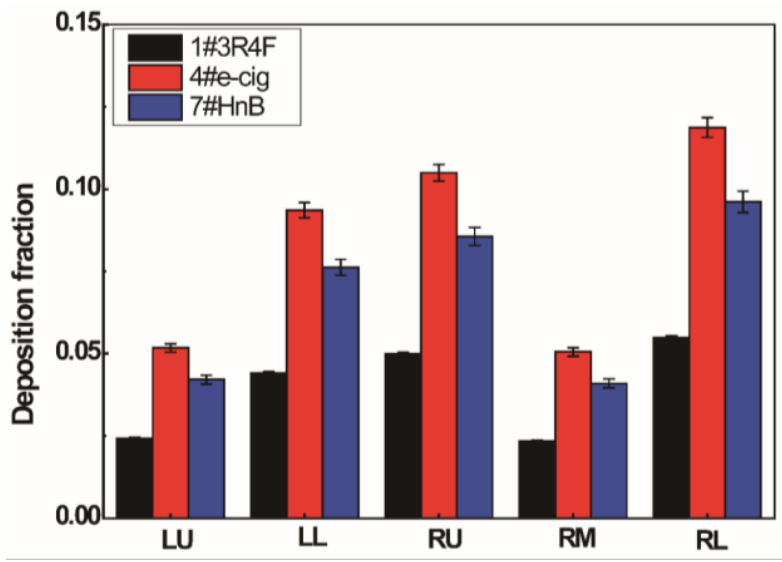

Fig. 6. Deposition fraction in different lobes of the lung for the three tobacco products. Abbreviations: LL, left lower lung lobe; LU, left upper lung lobe; RL, right lower lung lobe; RM, right middle lung lobe; RU, right upper lung lobe.

the 3R4F cigarette, e-cigarette and $\mathrm{HnB}$ cigarette, showing the following trend in deposition trend fraction: left upper lobe $\approx$ right middle lobe $<$ left lower lobe $<$ right upper lobe $<$ right lower lobe. This trend is mainly related to the position of each lung lobe and the aerosol flow path. Among them, the left lower lobe has the longest flow path and a longer aerosol residence time, so it has a relatively higher deposition.

More specifically, as showed in Fig. 6, the deposition fraction was highest in the right lower lobe $(0.055,0.12$, and 0.096 for the 3R4F cigarette, e-cigarette and HnB product, respectively), accounting for about $28 \%$ of the total lung lobe deposition fraction in each case. Furthermore, the deposition fraction in the left lower, right upper and right lower lobe generally accounted for $75 \%$ of the total lung lobe deposition fraction. For all three tobacco products, therefore, the aerosol was mainly deposited in the right lower lobe, the right upper lobe and the left lower lobe of the lung. We compared the deposition fraction of the aerosols in the different lobes of the lungs among the three products. Across all five lung lobes, the deposition fraction followed the order: e-cigarette $>\mathrm{HnB}$ cigarette $>3 \mathrm{R} 4 \mathrm{~F}$ cigarette; in particular, for the e-cigarette, the deposition fraction in the right lower lobe was 1.23 and 2.16 times higher than that of the HnB product and 3R4F cigarette, respectively. The difference in deposition fraction among the lung lobes mainly stems from variations in lobe structure. The right lower lung lobe, which has more and longer bronchial passages, tends to have a higher deposition fraction.

Because the deposition fraction was highest in the right lower lobe for all products, we used this lobe as an example to investigate the particle size distribution of NC among the three products. The 3R4F cigarette, e-cigarette and $\mathrm{HnB}$ product had different particle NC size deposition distributions, peaking at about $200 \mathrm{~nm}, 25 \mathrm{~nm}$ and $50 \mathrm{~nm}$, respectively; and the peak value of the $\mathrm{HnB}$ product was higher than that of the $3 \mathrm{R} 4 \mathrm{~F}$ cigarette and e-cigarette, while the $3 \mathrm{R} 4 \mathrm{~F}$ cigarette had the smallest peak value (Fig. 7). 
The airways of the lungs comprise bronchial trees formed by thousands of branches; each bronchus in the lungs is then repeatedly branched into numerous bronchioles, which are further expanded into capsules to form alveoli. The MPPD model was used to simulate the deposition of aerosols in different generations of the airways in human lungs.

On the whole, the deposition patterns of aerosol from the 3R4F cigarette, e-cigarette and $\mathrm{HnB}$ product in different generations of airway were consistent (Fig. 8). The deposition fraction showed the trend of a rise followed by a decline in deposition with the increase in airway generation. The peak deposition fraction varied among the different lung lobes, but peak deposition mainly occurred in the $20^{\text {th }}$ to $24^{\text {th }}$ generation airways $\left(20^{\text {th }}\right.$ in the left upper; $23^{\text {rd }}$ in the right middle,

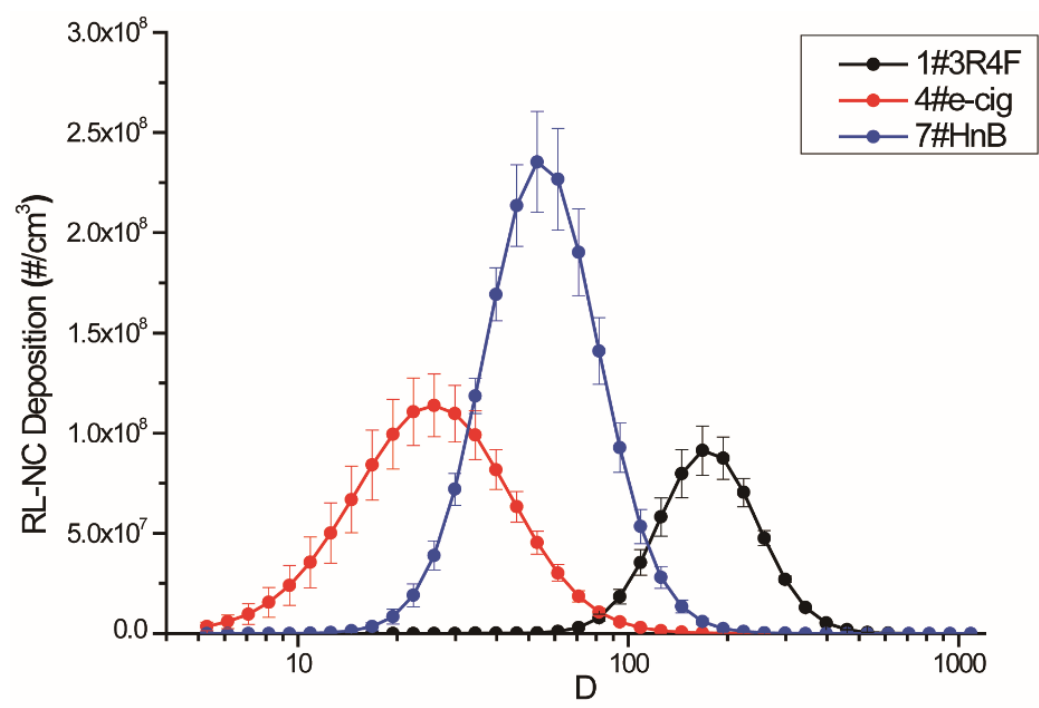

Fig. 7. Distribution of particle NC size deposition in the right lower $(\mathrm{RL})$ lung lobe for the three tobacco products.
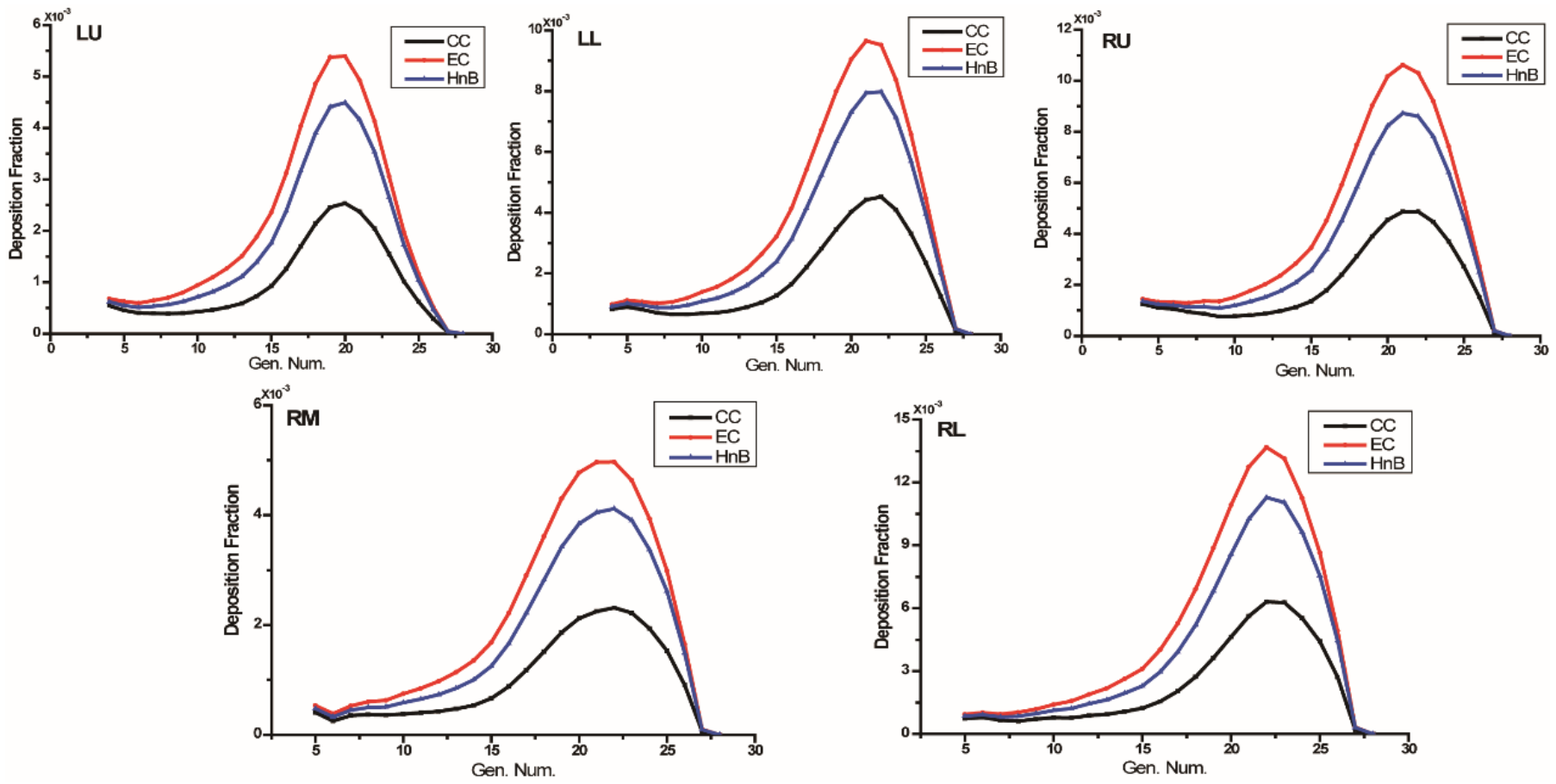

Fig. 8. Distribution of particle deposition fraction in increasing airway generations for the three tobacco products. (a) CC; (b) EC; (c) HnB. Abbreviations: LL, left lower lung lobe; LU, left upper lung lobe; RL, right lower lung lobe; RM, right middle lung lobe; $\mathrm{RU}$, right upper lung lobe. 
right upper and left lower; and $24^{\text {th }}$ in right lower), which is consistent with a previous study (Manigrasso et al., 2015). The peak value was highest in the right lower lobe, and decreased in the following order: right lower > right upper > left lower > left upper > right middle. The total deposition fraction for the three tobacco product aerosols in the different airway generations of the lungs showed the trend: e-cigarette $>\mathrm{HnB}$ product $>3 \mathrm{R} 4 \mathrm{~F}$ cigarette. Comparing the deposition fraction among the three products, the e-cigarette and $\mathrm{HnB}$ product had a much higher deposition fraction relative to the $3 \mathrm{R} 4 \mathrm{~F}$ cigarette, which is probably due to the smaller aerosol particles of the e-cigarette and $\mathrm{HnB}$ product.

\section{CONCLUSION}

In the present study, the physical properties of aerosols generated by conventional cigarettes, e-cigarettes and HnB products were compared by DMS-SCS. The measured data were then applied to the MPPD model to predict the distribution and deposition of the types of aerosol in different regions of the human respiratory tract (head airway, tracheobronchial, pulmonary) and different lobes of the human lungs. The model showed that the deposition fraction of the e-cigarette aerosol in the three regions of the human airway was higher than that of the HnB product and $3 R 4 F$ cigarette. Among the three airway regions, the NC of deposited particles was highest in the pulmonary region; and the particle number deposition fraction of the e-cigarette and $\mathrm{HnB}$ product was higher than that of the 3R4F cigarette. The deposition fraction of smoke in different lung lobes also differed significantly: the deposition fraction was the highest in the right lower lobe for all three tobacco products. In terms of airway generation, the deposition fraction peaked in the $20^{\text {th }}$ to $24^{\text {th }}$ generation airways of the lobes. The particle NC size distributions in the lung lobes and airway generations were basically in line with the airway regions.

Regarding the three tobacco products, the aerosol from the e-cigarette and $\mathrm{HnB}$ product had a higher deposition fraction both in total and in each of the three respiratory regions. In other words, even though the aerosols from the e-cigarette and $\mathrm{HnB}$ product do not contain toxic components similar to those present in the aerosol from a conventional cigarette, there remains a risk of using e-cigarettes and $\mathrm{HnB}$ products due to the higher deposition fraction. It should be noted that the smoke aerosol used for deposition modeling was generated by SCS under the standard puffing regime, which is different from the real inhalation patterns of smokers. The real inhalation patterns with various puffing topographies may influence the size of particles and further influence the regional deposition in the respiratory system. Research into the deposition of tobacco product aerosol in the human respiratory tract, combined with knowledge of the harmful constituents of the aerosol, will provide important information for risk assessment of the inhalation toxicology for humans using cigarette and new tobacco products. In addition, based on the distribution of nicotine in the gas/particle phase, the aerosol deposition results can be used to evaluate nicotine transfer in individuals using tobacco products.

\section{ACKNOWLEDGMENT}

This work was supported by National Natural Science Foundation of China (Grant no. 21705164), Science and Technology Development Foundation of Zhengzhou Tobacco Research Institute of CNTC (Grant no. 312016CA0220), Science and Technology Major Project of China National Tobacco Corporation (110201901002(XX-02)).

\section{NOTES}

The authors declare no competing financial interest.

\section{SUPPLEMENTARY MATERIAL}

Supplementary data associated with this article can be found in the online version at https://doi.org/10.4209/aaqr.200241 


\section{REFERENCES}

Adam, T., McAughey, J., McGrath, C., Mocker, C., Zimmermann, R. (2009). Simultaneous on-line size and chemical analysis of gas phase and particulate phase of cigarette mainstream smoke. Anal. Bioanal. Chem. 394, 1193-1203. https://doi.org/10.1007/s00216-009-2784-y

Alderman, S.L., Ingebrethsen, B.J. (2011). Characterization of mainstream cigarette smoke particle size distributions from commercial cigarettes using a DMS500 fast particulate spectrometer and smoking cycle simulator. Aerosol Sci. Technol. 45, 1409-1421. https://doi.org/10.1080/02 786826.2011.596862

Anjilvel, S., Asgharian, B. (1995). A multiple-path model of particle deposition in the rat lung. Fundam. Appl. Toxicol. 28, 41-50. https://doi.org/10.1006/faat.1995.1144

Asgharian, B., Price, O.T., Rostami, A.A., Pithawalla, Y.B. (2018). Deposition of inhaled electronic cigarette aerosol in the human oral cavity. J. Aerosol Sci. 116, 34-47. https://doi.org/10.1016/ j.jaerosci.2017.11.014

Asgharian, B., Price, O.T., Yurteri, C. ., Dickens, C., Mcaughey, J. (2014). Component-specific, cigarette particle deposition modeling in the human respiratory tract. Inhalation Toxicol. 26, 36-47. https://doi.org/10.3109/08958378.2013.851305

Bair, W. (1995). The ICRP human respiratory tract model for radiological protection. Radiat. Prot. Dosim. 60, 307-310. https://doi.org/10.1093/oxfordjournals.rpd.a082732

Baker, R.R. (2006). Smoke generation inside a burning cigarette: Modifying combustion to develop cigarettes that may be less hazardous to health. Prog. Energy Combust. Sci. 32, 373-385. https://doi.org/10.1016/j.pecs.2006.01.001

Barua, R.S., Ambrose, J.A. (2013). Mechanisms of coronary thrombosis in cigarette smoke exposure. Arterioscler. Thromb. Vasc. Biol. 33, 1460-1467. https://doi.org/10.1161/ATVBAHA 112.300154

Boue, S., Goedertier, D., Hoeng, J., Kuczaj, A., Majeed, S., Mathis, C., May, A., Phillips, B., Peitsch, M. C., Radtke, F., Schlage, W.K., Tan, W.T., Vanscheeuwijck, P. (2020). State-of-the-art methods and devices for the generation, exposure, and collection of aerosols from heat-not-burn tobacco products. Toxicol. Res. Appl. 4, 1-40. https://doi.org/10.1177/2397847319897869

Broday, D.M., Robinson, R. (2003). Application of cloud dynamics to dosimetry of cigarette smoke particles in the lungs. Aerosol Sci. Technol. 37, 510-527. https://doi.org/10.1080/0278682030 0969

Carvalho, T.C., Peters, J.I., Williams III, R.O. (2011). Influence of particle size on regional lung deposition-What evidence is there? Int. J. Pharm. 406, 1-10. https://doi.org/10.1016/j.ijphar m.2010.12.040

Chen, C. (2017). Change and challenge: Outlook for development of new tobacco products. Acta Tabacaria Sin. 23, 14-18. https://doi.org/10.16472/j.chinatobacco.2017.082

Church, T.R., Anderson, K.E., Caporaso, N.E., Geisser, M.S., Le, C.T., Zhang, Y., Hecht, S.S. (2009). A prospectively measured serum biomarker for a tobacco-specific carcinogen and lung cancer in smokers. Cancer Epidemiol. Biomarkers. Prev. 18, 260-266. https://doi.org/10.1158/10559965

Cui, H., Yurteri, C.U., Cabot, R., Xie, F., Liu, H. (2020). Characterization of mainstream cigarette smoke aerosol by size-fractionated chemical analysis of nicotine, solanesol, and tobaccospecific nitrosamines. Part. Sci. Technol. 38, 587-595. https://doi.org/10.1080/02726351.201 9.1567636

Delfino, R.J., Staimer, N., Tjoa, T., Arhami, M., Polidori, A., Gillen, D.L., Sioutas, C. (2010). Association of biomarkers of systemic inflammation with organic components and source tracers in quasi-ultrafine particles. Environ. Health Perspect. 118, 756-762. https://doi.org/10. 1289/ehp.0901407

Duan, Y., Zhao, W., Yang, J., Han, J., Sun, Z., Yang, L., Chen, Y. (2015). Research on particle size distribution in traditional cigarette and electronic cigarette smoke aerosols. Acta Tabacaria Sin. https://doi.org/10.16472/j.chinatobacco.2014.298

Geiser, M., Rothen-Rutishauser, B., Kapp, N., Schürch, S., Kreyling, W., Schulz, H., Gehr, P. (2005). Ultrafine particles cross cellular membranes by nonphagocytic mechanisms in lungs and in cultured cells. Environ. Health Perspect. 113, 1555-1560. https://doi.org/10.1289/ehp.8006 
Geiss, O., Kotzias, D. (2007). Tobacco, cigarettes and cigarette smoke - An overview. EUR Scientific and Technical Research Series. Office for Official Publications of the European Communities, Luxembourg. http://publications.jrc.ec.europa.eu/repository/bitstream/JRC374 72/7472\%20-\%20EUR22783EN_Geiss_Kotzias.pdf

Hackshaw, A., Morris, J.K., Boniface, S., Tang, J.L., Milenković, D. (2018). Low cigarette consumption and risk of coronary heart disease and stroke: meta-analysis of 141 cohort studies in 55 study reports. BMJ 360, j5855. https://doi.org/10.1136/bmj.j5855

Hinds, W.C. (1978). Size characteristics of cigarette smoke. Am. Ind. Hyg. Assoc. J. 39, 48-54. https://doi.org/10.1080/0002889778507712

Hinds, W.C. (1999). Aerosol technology: Properties, behavior, and measurement of airborne particles. John Wiley and Sons.

Hofmann, W. (2011). Modelling inhaled particle deposition in the human lung-A review. J. Aerosol Sci. 42, 693-724. https://doi.org/10.1016/j.jaerosci.2011.05.007

Holmberg, R., Yeatts, L. (1976). Particle size distribution of mainstream tobacco and marijuana smoke. Analysis using the electrical aerosol analyzer. Am. Rev. Respir. Dis. 140, 202-205. https://doi.org/10.1164/ajrccm/140.1.202

International Organization for Standardization (ISO) (2000). ISO 3308: 2000-04-15: Routine Analytical Cigarette-smoking Machine--Definition and Standard Conditions. International Organization for Standardization. https://www.iso.org/standard/28325.html

International Organization for Standardization (ISO) (2018). ISO 20768:2018 I. Vapour products Routine analytical vaping machine - Definitions and standard conditions. International Organization for Standardization. https://www.iso.org/standard/69019.html

Johnson, T.J., Olfert, J.S., Cabot, R., Treacy, C., Yurteri, C.U., Dickens, C., Symonds, J.P. (2015). Transient measurement of the effective particle density of cigarette smoke. J. Aerosol Sci. 87, 63-74. https://doi.org/10.1016/j.jaerosci.2015.05.006

Kane, D.B., Asgharian, B., Price, O.T., Rostami, A., Oldham, M.J. (2010). Effect of smoking parameters on the particle size distribution and predicted airway deposition of mainstream cigarette smoke. Inhalation Toxicol. 22, 199-209. https://doi.org/10.3109/08958370903161224

Kijowski, J. (1985). A review of particle size studies on cigarette smoke. Product Design MSA Collection. https://www.industrydocuments.ucsf.edu/docs/spbk0037

Kleinstreuer, C., Zhang, Z. (2010). Airflow and particle transport in the human respiratory system. Annu. Rev. Fluid Mech. 42, 301-334. https://doi.org/10.1146/annurev-fluid-121108-145453

Kleinstreuer, C., Feng, Y. (2013). Computational analysis of non-spherical particle transport and deposition in shear flow with application to lung aerosol dynamics--A review. J. Biomech. Eng. 135, 021008. https://doi.org/10.1115/1.4023236

Leaderer, B.P., Cain, W.S., Isseroff, R., Berglund, L.G. (1984). Ventilation requirements in buildings - II. Particulate matter and carbon monoxide from cigarette smoking. Atmos. Environ. 18, 99-106. https://doi.org/10.1016/0004-6981(84)90232-4

Li, X., Yan, C., Patterson, R.F., Zhu, Yujiao, Yao, X., Zhu, Yifang, Ma, S., Qiu, X., Zhu, T., Zheng, M. (2016). Modeled deposition of fine particles in human airway in Beijing, China. Atmos. Environ. 124, 387-395. https://doi.org/10.1016/j.atmosenv.2015.06.045

Liang, J.S., An, J.L., Wang, H.L., Zhang, Y.X., Wang, J.X., Shi, S.S., Wang, X. (2017). Modeled deposition of fine particles in human airway in northern suburb of Nanjing. Huan Jing Ke Xue 38, 1743-1752. https://doi.org/10.13227/j.hjkx.201610040

Manigrasso, M., Buonanno, G., Fuoco, F.C., Stabile, L., Avino, P. (2015). Aerosol deposition doses in the human respiratory tree of electronic cigarette smokers. Environ. Pollut. 196, 257-267. https://doi.org/10.1016/j.envpol.2014.10.013

Martins, L.D., Martins, J.A., Freitas, E.D., Mazzoli, C.R., Goncalves, F.L., Ynoue, R.Y., Andrade, M.D. (2010). Potential health impact of ultrafine particles under clean and polluted urban atmospheric conditions: A model-based study. Air Qual. Atmos Health 3, 29-39. https://doi.org/10.1007/s1 1869-009-0048-9

McCusker, K., Hiller, F., Wilson, J., McLeod, P., Sims, R., Bone, R. (1982). Dilution of cigarette smoke for real time aerodynamic sizing with a SPART analyzer. J. Aerosol Sci. 13, 103-110. https://doi.org/10.1016/0021-8502(82)90055-6

Mellat, M., Momtazi Borojeni, A. A., Sahebkar, A., Ghanei, M. (2017). Adapting the ICRP model to predict regional deposition of the pharmaceutical aerosols inhaled through DPIs and nebulizers. 
J. Drug Delivery Sci. Technol. 37, 81-87. https://doi.org/10.1016/j.jddst.2016.12.002

Meng, X., Ma, Y., Chen, R., Zhou, Z., Chen, B., Kan, H. (2013). Size-fractionated particle number concentrations and daily mortality in a Chinese city. Environ. Health Perspect. 121, 1174-1178. https://doi.org/10.1289/ehp.1206398

Miller, F.J., Asgharian, B., Schroeter, J.D., Price, O. (2016). Improvements and additions to the Multiple Path Particle Dosimetry model. J. Aerosol Sci. 99, 14-26. https://doi.org/10.1016/j.jae rosci.2016.01.018

Patterson, R.F., Zhang, Q., Zheng, M., Zhu, Y. (2014). Particle deposition in respiratory tracts of school-aged children. Aerosol Air Qual. Res, 14, 64-73. https://doi.org/10.4209/aaqr.2013.04. 0113

Penttinen, P., Timonen, K., Tiittanen, P., Mirme, A., Ruuskanen, J., Pekkanen, J. (2001). Ultrafine particles in urban air and respiratory health among adult asthmatics. Eur. Respir. J. 17, 428435. https://doi.org/10.1183/09031936.01.17304280

Pichelstorfer, L., Hofmann, W., Winkler-Heil, R., Yurteri, C.U., McAughey, J. (2016). Simulation of aerosol dynamics and deposition of combustible and electronic cigarette aerosols in the human respiratory tract. J. Aerosol Sci. 99, 125-132. https://doi.org/10.1016/j.jaerosci.2016.01.017

Protano, C., Manigrasso, M., Avino, P., Vitali, M. (2017). Second-hand smoke generated by combustion and electronic smoking devices used in real scenarios: Ultrafine particle pollution and age-related dose assessment. Environ. Int. 107, 190-195. https://doi.org/10.1016/j.envint. 2017.07.014

Rodgman, A., Perfetti, T.A. (2008). The Chemical Components of Tobacco and Tobacco Smoke. CRC Press. https://doi.org/10.1201/9781420078848.

Rostami, A.A. (2009). Computational modeling of aerosol deposition in respiratory tract: A review. Inhalation Toxicol. 21, 262-290. https://doi.org/10.1080/08958370802448987

Roy, M., Becquemin, M., Bouchikhi, A. (1991). Ventilation rates and lung volumes for lung modelling purposes in ethnic groups. Radiat. Prot. Dosim. 38, 49-55. https://doi.org/10.1093/r $\mathrm{pd} / 38.1-3.49$

Sahu, S.K., Tiwari, M., Bhangare, R.C., Pandit, G.G. (2013). Particle size distribution of mainstream and exhaled cigarette smoke and predictive deposition in human respiratory Tract. Aerosol Air Qual. Res. 13, 324-332. https://doi.org/10.4209/aaqr.2012.02.0041

Si, X., Tang, J., Zhu, R., Han, J., You, J., Li, Z., Jiang, W., Su, Z., Miao, M., Liu, Z. (2018). Aerosol particle size distribution from an electrical heat-not-burn product under ISO and $\mathrm{HCl}$ smoking regimes. Tobacco Sci. Technol. 21, 47-52. https://doi.org/10.16135/j.issn1002-0861.2017.0501

Simonavicius, E., McNeill, A., Shahab, L., Brose, L.S. (2019). Heat-not-burn tobacco products: A systematic literature review. Tobacco Control 28, 582-594. https://doi.org/10.1136/tobaccoco ntrol-2018-054419

Sosnowski, T.R. (2011). Importance of airway geometry and respiratory parameters variability for particle deposition in the human respiratory tract. J. Thorac. Dis, 3, 153-155. https://doi.org/ 10.3978/j.issn.2072-1439.2011.06.01

Sosnowski, T.R., Kramek-Romanowska, K. (2016). Predicted Deposition of e-cigarette aerosol in the human lungs. J. Aerosol Med. Pulm. Drug Delivery 29, 299-309. https://doi.org/10.1089/ja mp.2015.1268

Sosnowski, T.R., Odziomek, M. (2018). Particle size dynamics: toward a better understanding of electronic cigarette aerosol interactions with the respiratory system. Front. Physiol. 9, 853. https://doi.org/10.3389/fphys.2018.00853

Symonds, J.P., Reavell, K.S.J., Olfert, J.S., Campbell, B.W., Swift, S.J. (2007). Diesel soot mass calculation in real-time with a differential mobility spectrometer. J. Aerosol Sci. 38, 52-68. https://doi.org/10.1016/j.jaerosci.2006.10.001

U.S. Department of Health and Human Services (2014). The Health Consequences of Smoking50 Years of Progress: A Report of the Surgeon General. U.S. Department of Health and Human Services, Centers for Disease Control and Prevention, National Center for Chronic Disease Prevention and Health Promotion, Office on Smoking and Health. https://www.ncbi.nlm.nih.go v/books/NBK294315/

World Health Organization (WHO) (2008). WHO report on the global tobacco epidemic, 2008: The MPOWER package. World Health Organization. https://www.who.int/tobacco/mpower/2008/en Zhang, Y., Sumner, W., Chen, D.R. (2012). In vitro particle size distributions in electronic and 
conventional cigarette aerosols suggest comparable deposition patterns. Nicotine Tob. Res. 15, 501-508. https://doi.org/10.1093/ntr/nts165

Zhe, Z., Kleinstreuer, C., Hyun, S. (2012). Size-change and deposition of conventional and composite cigarette smoke particles during inhalation in a subject-specific airway model. J. Aerosol Sci. 46, 34-52. https://doi.org/10.1016/j.jaerosci.2011.12.002 